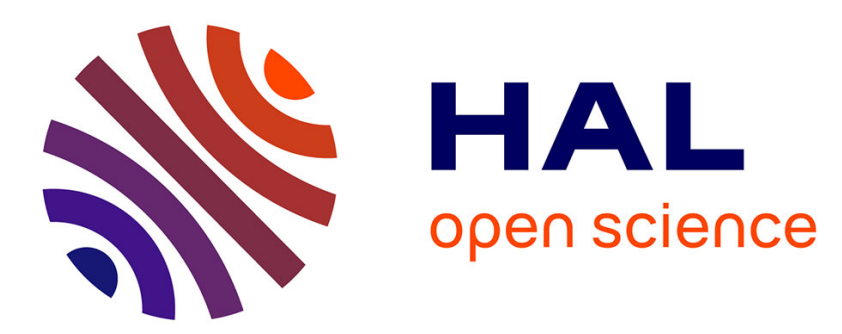

\title{
Magnetic order in FeCl3 intercalated graphite by neutron diffraction
}

Ch. Simon, F. Batallan, I. Rosenman, J. Schweitzer, H. Lauter, R. Vangelisti

\section{To cite this version:}

Ch. Simon, F. Batallan, I. Rosenman, J. Schweitzer, H. Lauter, et al.. Magnetic order in FeCl3 intercalated graphite by neutron diffraction. Journal de Physique Lettres, 1983, 44 (15), pp.641-647. 10.1051/jphyslet:019830044015064100 . jpa-00232244

\section{HAL Id: jpa-00232244 https://hal.science/jpa-00232244}

Submitted on 1 Jan 1983

HAL is a multi-disciplinary open access archive for the deposit and dissemination of scientific research documents, whether they are published or not. The documents may come from teaching and research institutions in France or abroad, or from public or private research centers.
L'archive ouverte pluridisciplinaire HAL, est destinée au dépôt et à la diffusion de documents scientifiques de niveau recherche, publiés ou non, émanant des établissements d'enseignement et de recherche français ou étrangers, des laboratoires publics ou privés. 


\title{
Magnetic order in $\mathrm{FeCl}_{3}$ intercalated graphite by neutron diffraction
}

\author{
Ch. Simon, F. Batallan, I. Rosenman
}

Groupe de Physique des Solides de l'Ecole Normale Supérieure (*), Tour 23, 2, place Jussieu, 75251 Paris Cedex 05, France

\section{J. Schweitzer}

DN/RFG, Centre d'Etudes Nucléaires, 85X, 38041 Grenoble Cedex, France and Institut Laüe-Langevin, 156X, 38042 Grenoble Cedex, France

\author{
H. Lauter \\ Institut Laüe-Langevin, 156X, 38042 Grenoble Cedex, France \\ and R. Vangelisti \\ Laboratoire de Chimie du Solide Minéral, Service de Chimie Minérale Appliquée (A. Herold) (*), \\ Université de Nancy-I, BP 239, 54506 Vandouvre les Nancy Cedex, France
}

(Reçu le 28 mars 1983, révisé le 4 mai, accepté le ler juin 1983)

\begin{abstract}
Résumé. - Nous avons étudié par diffraction de neutrons à basse température les deux premiers stades de $\mathrm{FeCl}_{3}$ intercalé dans le graphite. Nous avons trouvé dans les deux cas que des corrélations bidimensionnelles se développent au-dessous de $30 \mathrm{~K}$. Nous observons à $3,8 \mathrm{~K}$ dans le seul premier stade une transition de cette phase 2-D à un ordre 3-D sans changement de la structure dans le plan. Cet ordre intra-planaire correspond à une modulation magnétique incommensurable de vecteur de propagation $0,394 \mathbf{a}^{*}$.
\end{abstract}

\begin{abstract}
We have investigated the magnetic properties of the first and second stage intercalates of $\mathrm{FeCl}_{3}$ in graphite by neutron diffraction at low temperatures. We have found that in both stages strong 2-D magnetic correlations develop below $30 \mathrm{~K}$. In the first stage we observe at $3.8 \mathrm{~K}$ a transition from the 2-D phase to a 3-D order. The in-plane order remains the same and corresponds to an incommensurate magnetic modulation of propagation vector $0.394 \mathrm{a}^{*}$.
\end{abstract}

(*) Laboratoire Associé au C.N.R.S. 


\section{Introduction.}

We present in this letter the first direct study of the magnetic order at low temperatures in a graphite intercalation compound (GIC) namely the $\mathrm{FeCl}_{3}-\mathrm{GIC}$ via neutron diffraction.

Some GICs with transition metal chlorides such as $\mathrm{FeCl}_{3}, \mathrm{CoCl}_{2}$ or $\mathrm{NiCl}_{2}$, present a magnetic order at sufficiently low temperatures. This order is associated with the presence of magnetic ions in the intercalated layers. The neutron diffraction method is particularly efficient to study this order in the rather complex cases because it is then the only method to give unambiguous results.

A special feature found in the GICs, namely the possibility of preparing different stages (i.e. the number of carbon layers between two adjacent intercalate layers) allows simple variation of the distance, and hence of the interaction between magnetic ions in adjacent intercalate layers. This permits smooth passage from a 3-D to a 2-D magnetic order and leads finally at high temperatures to a disappearance of the 2-D order.

Karimov et al. [1] were the first to report magnetic order in a $\mathrm{GIC}\left(\mathrm{FeCl}_{3}\right)$, by studying magnetic susceptibility at low temperatures. Specific heat [2] and Mössbauer effect [3, 4] contributed also to the knowledge of these transitions. The conflicting interpretations given in these works show that the magnetic order is rather complex, and neutron diffraction is then a particularly useful tool.

We present here the first part of our studies on the magnetic order in the GICs by neutron diffraction : the results on $\mathrm{FeCl}_{3}$-GIC of stage one and two.

\section{Samples and experimental technique.}

Our study was made at the high flux neutron reactor at the Institute Laüe-Langevin on the powder diffractometer $\mathrm{D} 2$, between $1.5 \mathrm{~K}$ and $40 \mathrm{~K}$. The wavelength of the neutrons was $1.22 \AA$.

The powder samples of $\mathrm{FeCl}_{3}$-GIC were prepared by the two-zone vapour transport method [5], and put in a sealed vanadium container in the presence of helium gas. Their weight was about $5 \mathrm{~g}$. The nature and quality of the samples were checked by $\mathrm{X}$-ray and neutron diffraction. We found that they were pure first- and second-stage compounds of $\mathrm{FeCl}_{3}$. We have obtained by weight analysis the chemical formulae $\mathrm{C}_{7.9} \mathrm{FeCl}_{3}$ for the first-stage compound (instead of the theoretical formula $\mathrm{C}_{6.12} \mathrm{FeCl}_{3}$ ) and $\mathrm{C}_{12} \mathrm{FeCl}_{3}$ for the second-stage compound (instead of $\mathrm{C}_{12.3} \mathrm{FeCl}_{3}$ ).

The crystallographic structure of the FeCl-GIC is now well known [6,7]. The carbon layers have the same structure as the pristine graphite $(2.465 \AA)$. The $\mathrm{FeCl}_{3}$ layers in the GIC have almost the same structure as in bulk $\mathrm{FeCl}_{3}$ : a hexagonal cell of iron rotated 30 degrees from the carbon cell, with a cell parameter of $6.12 \AA$. The two lattices are thus incommensurate. The period along the $c$-axis is $9.45 \AA$ and $12.9 \AA$ respectively for the first-and second-stage compounds. One should notice that the stacking faults are particularly important in this compound and they influence strongly the intensities of the nuclear peaks. Thus they have been taken into account in the determination of the crystallographic structure [7].

\section{Results.}

In order to investigate the magnetic order in the powder samples we have recorded the neutron diffraction patterns at several temperatures. All the nuclear peaks can be indexed in agreement with the crystallographic structure. This has also permitted us to check the quality of the sample. In particular the comparison between the calculated and the experimental intensities did not show any obvious effect of preferential orientation in our samples. The magnetic peaks were obtained in the small angle region $\left(5^{\circ}<2 \theta<15^{\circ}\right)$ by performing the point by point subtraction from the data of the spectrum obtained at high temperature where the magnetic order is expected to disappear. Though the positions of the peaks are independent of the temperature and of the stage, the shapes of these peaks are very different (see in Fig. 1). For the first-stage compound 
at very low temperatures (below $3.5 \mathrm{~K}$ ) the peaks are symmetric (Fig. $1 a$ ). In the two other cases (first-stage compound above $4 \mathrm{~K}$ and the second-stage compound) the magnetic peaks are asymmetric and present a Warren shape [8] characteristic of two-dimensional correlations (Figs. $1 b$ and $1 c$ ).
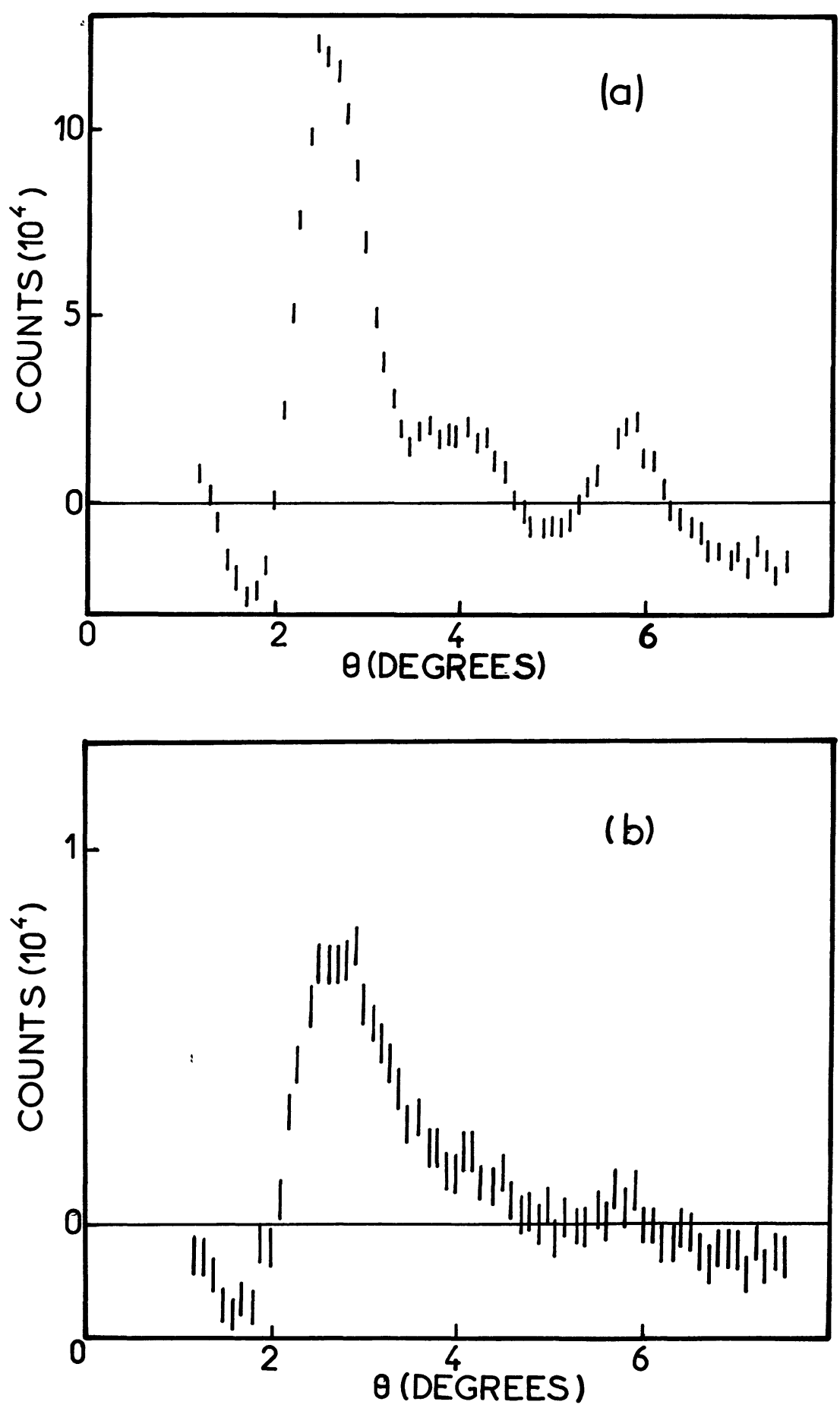


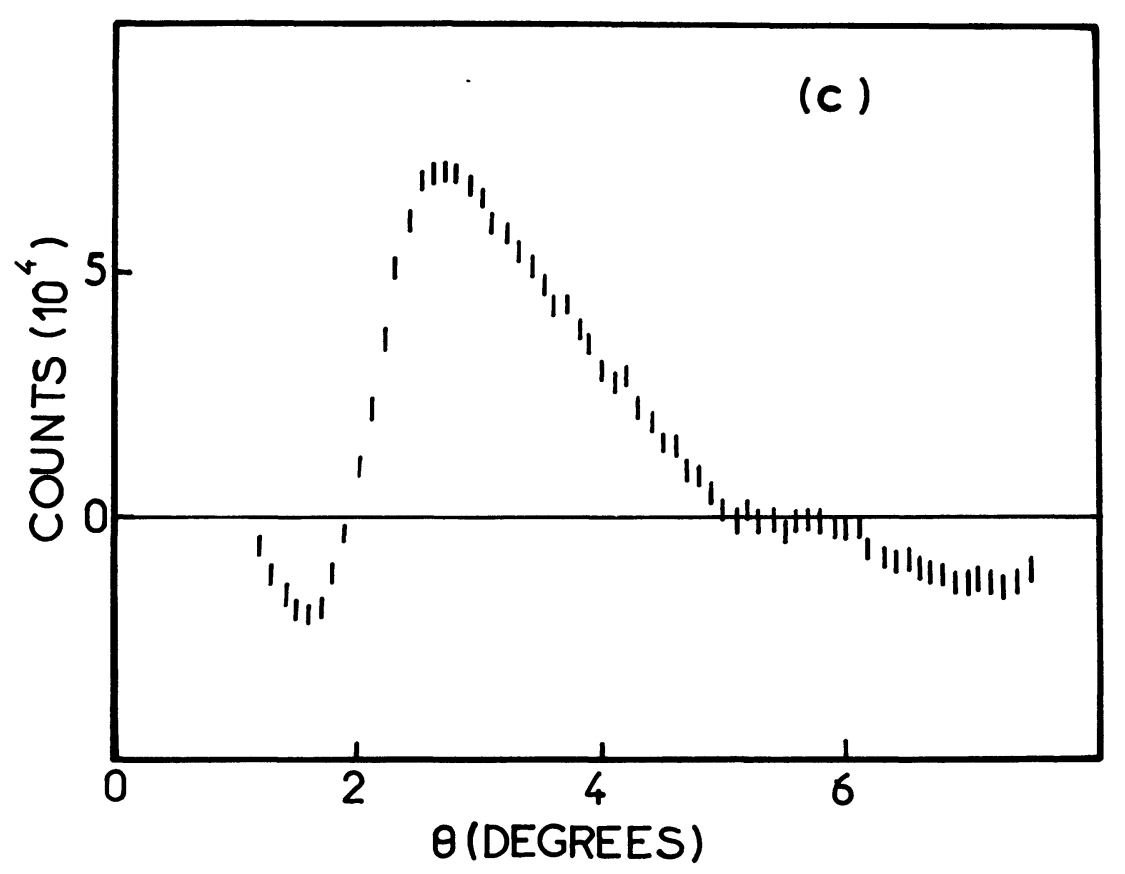

Fig. 1. - Three typical difference patterns between the temperature $T$ and $29 \mathrm{~K}: 1 a$ ) stage $1, T=1.52 \mathrm{~K}$; 1b) stage $1, T=4 \mathrm{~K} ; 1 c$ ) stage $2, T=1.52 \mathrm{~K}$.

In figure 2 we have plotted the temperature dependence of the integrated intensity of the main magnetic peak $\left(\theta=2.60^{\circ}\right)$ for both stages. For the stage-two compound the intensity of this peak increases slowly when the temperature decreases from $30 \mathrm{~K}$ down to $1.5 \mathrm{~K}$ and does not present any discontinuity in this range. In the first-stage compound, the intensity of the peak is varying smoothly down to $4 \mathrm{~K}$ but a phase transition occurs between $4 \mathrm{~K}$ and $3.5 \mathrm{~K}$ : the peaks then become symmetric and their intensities increase abruptly. This transition is confirmed by our specific heat measurements on the same sample [9] and is located at $3.8 \mathrm{~K}$. This transition was first observed by Karimov [1] and by several authors since.

The possibility of varying the stage allows the magnetic coupling in the $c$-direction to be changed. In the first-stage compound we have indeed observed the appearance of such a coupling along the $c$-direction at $3.8 \mathrm{~K}$. In the second-stage compound we have not observed such a transition down to $1.5 \mathrm{~K}$. The magnetic correlations may be indeed destroyed by the lower value of the magnetic coupling and the presence of more stacking faults.

We have found that in both stages for temperatures below $30 \mathrm{~K}$ the in-plane magnetic correlations are two-dimensional. This can be seen directly on the Warren-type shape of the diffraction peaks characteristic of 2-D systems. So that in this case the compound can be considered as an uncorrelated stacking of 2-D magnetic layers. This suggests that these peaks should be indexed as $(h k)$ streaks. They are located at $\theta=2.60^{\circ}, \theta=4.00^{\circ}$ and $\theta=5.80^{\circ}$. They can be indexed in the iron lattice as $(\delta, 0)$ for $\theta_{1},(1-\delta, 0)$ for $\theta_{2}$ and $(-\delta, 1)$ or $(-1+\delta, 1)$ for $\theta_{3}$ (Fig. 3). This corresponds to a magnetic modulation in the direction $\langle 10\rangle$ of relative wave length $\delta=0.394$ which is incommensurate with the iron lattice. Alternatively this can be seen as a modulation of the antiferromagnetism $(1 / 2,0)$ in the direction $\langle 10\rangle$ of wavelength $0.5-\delta$. The details of our study on this phase will be published elsewhere.

In the first-stage compound, another magnetic phase appears below $3.8 \mathrm{~K}$ which is not observed down to $1.5 \mathrm{~K}$ in the second-stage compound. In this phase the peaks are symmetric and cor- 

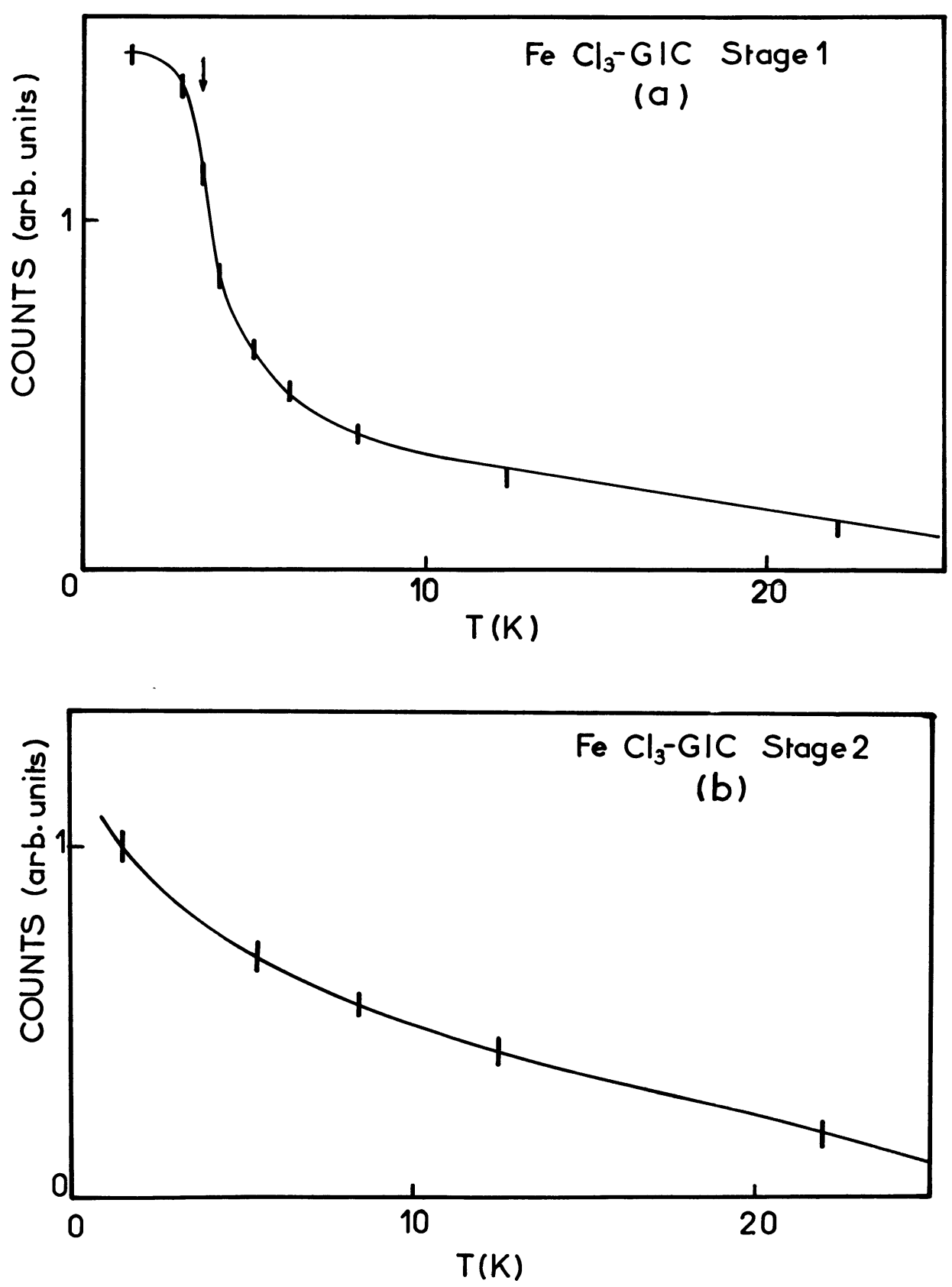

Fig. 2. - The integrated intensities of the main magnetic peak $(\theta=2.6$ degrees) plotted against the temperature. The arrow on figure $2 a$ corresponds to the transition observed in our specific heat measurements.

respond to a 3-D order. We have determined the magnetic structure of this phase : the magnetic order is made of the same incommensurate modulation of wavevector $\delta \mathbf{a}^{*}$ as in the 2-D phase and we assume a simple ferromagnetism along the $c$-direction. In table I we compare the intensities of the observed magnetic peaks and those predicted by our calculation for two different directions of the magnetic moments. This calculation does not take into account the stacking 


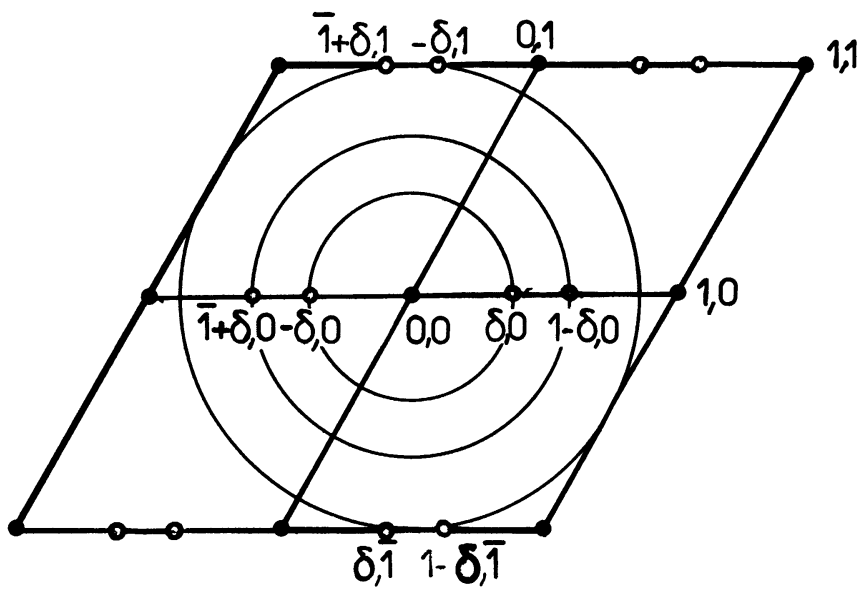

Fig. 3. - In-plane reciprocal lattice of the intercalated $\mathrm{FeCl}_{3}$. $\bullet$ represents the nuclear peaks, $\bigcirc$ the magnetic peaks. The three large circles are the magnetic peaks actually observed in our powder sample.

Table I. - Comparison between the calculated and the observed intensities (in arbitrary units) of the magnetic peaks in the 3-D phase of the first-stage $\mathrm{FeCl}_{3}-\mathrm{GIC}(T=1.52 \mathrm{~K})$. These results correspond to $4.76 \mu_{\mathrm{B}}$ per $\mathrm{Fe}^{3+}$.

\begin{tabular}{|l|c|c|c|}
\hline Thêta & \multicolumn{2}{|c|}{ Calculated values } & $\begin{array}{c}\text { Experimental } \\
\text { values }\end{array}$ \\
\hline & \multicolumn{2}{|c|}{$\begin{array}{c}\text { direction of the moments } \\
\langle 010\rangle\end{array}$} & \\
\hline $2.6^{\circ}$ & 2340 & 3120 & 3120 \\
\hline $4^{\circ}$ & 450 & 600 & 620 \\
$4.5^{\circ}$ & 1760 & 630 & 60 \\
\hline $5.4^{\circ}$ & 66 & 40 & 760 \\
$5.7^{\circ}$ & 140 & 460 & \\
\hline
\end{tabular}

faults. However table I shows that this simple model allows us to obtain the direction and the value of the moments : they lie along the $c$-axis and $4.76 \mu_{\mathrm{B}}$ per iron ion are ordered at low temperature $(1.5 \mathrm{~K})$. This last value must be taken cautiously because of uncertainties on both the intensities of the magnetic peaks (see Table I) and in the determination of the normalization factor for the intensities of the nuclear peaks. A more elaborate model which takes into account the stacking fault is now in progress. In any case, as $\mathrm{Fe}^{3+}$ ions own $5 \mu_{\mathrm{B}}$, most of their moments are ordered at $1.5 \mathrm{~K}$ in this phase. 
These results present some similarities with the magnetic order found in bulk $\mathrm{FeCl}_{3}$ which is a Heisenberg helicoidal in-plane modulation in the $\langle 1,4,0\rangle$ direction [10]. However the great difference of electronic properties (a very large charge transfer occurs in the GICs between the graphite and the intercalated layers) makes it difficult to be sure that the present system is also Heisenberg. Different authors actually claimed that it is an Ising system [1] or that the moments lie in the layers plane [4]. A more detailed study remains to be made. Following its conclusions the nature of the 2-D phase should be understood and in particular if it is an actual long-range 2-D order [1] or has only very strong short-range correlations [2].

\section{References}

[1] Karimov, Yu. S., Zvarykina, A. V., Novikov, Yu. N., Sov. Phys. Solid. State 13 (1972) 2388.

[2] OnN, D. G., Alexander, M. G., Ritsko, J. J., Flandrois, S., J. Appl. Phys. 53 (1982) 2751.

[3] Ohhashi, K., Tsujikawa, I., J. Phys. Soc. Japan 36 (1974) 4221.

[4] Holwein, D., Readman, P. W., Chamberod, A., Coey, J. M. D., Phys. Status Solidi (b) 64 (1974) 305.

[5] Wachnik, R., Vangelisti, R., McRae, E., Herold, A., Vogel, F. L., Proceedings of 3rd Int. Carbon Conf., Baden Baden, June 1980, 120.

[6] Cowley, J. M., Ibers, J. A., Acta Cryst. 9 (1956) 412.

[7] Rousseaux, F., Vangelisti, R., Lelaurain, M., Herold, A., Planchon, A., Tchoubar, D., TCHOUBAR, C., in extended abstracts of the 15th biennial conference on carbon, University of Pennsylvania (1981).

[8] Warren, B. E., Phys. Rev. 59 (1941) 693.

[9] To be published.

[10] Cable, J. W., Wilkinson, M. K., Wollan, E. D., Koehler, W. C., Phys. Rev. 127 (1962) 714. 